\title{
O que é cognitivismo?
}

\author{
Adriana Munhoz Carneiro ${ }^{1}$
}

Castanõn, Gustavo (2007). O que é cognitivismo? Fundamentos filosóficos. São Paulo: EPU. 141 p.

Em objeção aos métodos behavioristas e psicanalíticos utilizados, surge o cognitivismo. Diferentemente do imaginado, este movimento provém de disciplinas externas à psicologia, tais como Engenharia, Lingüística, Filosofia da Ciência, Matemática e Neuropsicologia, tendo como principal objetivo o estudo da consciência e da mente. Apesar de sua importância, o cognitivismo, que gerou subcorrentes como a psicologia cognitiva e a ciência cognitiva, carece de descrições na literatura, motivo pelo qual Gustavo Castanõn resolve escrever esta obra.

O início do livro conta com uma apresentação escrita por João de Fernandes Teixeira, que considera a obra inovadora e de grande utilidade por sua interpretação histórica da revolução cognitivista. Em seguida, Castanõn, ao escrever a introdução, relata a dificuldade de se encontrar livros de história da psicologia que se dediquem a descrever os fundamentos filosóficos desta abordagem e apresenta sua obra como uma tentativa de suprir essa necessidade aparente do cenário da psicologia.

Assim, o livro visa proporcionar um breve conhecimento e reflexão acerca dos fenômenos epistemológicos e filosóficos que influenciaram esta corrente. Está organizado em 5 capítulos, os quais, com exceção do último, são introduzidos por um epílogo e contêm subcapítulos, que facilitam a leitura e entendimento.

No capítulo inicial, o autor realiza um retrospecto acerca dos movimentos antecedentes ao cognitivismo e vai ampliando os horizontes do leitor ao enfocar, gradativamente, os movimentos e teóricos responsáveis por fundamentar e possibilitar o surgimento dessa teoria. $\mathrm{O}$ racionalismo crítico de Popper é colocado como o movimento mais importante para o surgimento e aceitação do cognitivismo, em razão da mudança na visão da pesquisa científica e da aceitação acerca dos estudos de processos cognitivos que propiciou. Ainda neste capítulo, o autor aborda a psicologia cognitiva dos dias atuais e os avanços científicos que alavancaram o cognitivismo, como a chegada do computador e o interesse pela compreensão dos processos cognitivos de forma mentalista, o que proporcionou o surgimento da inteligência artificial. Um outro fator seria a obra de Chomsky, que derrubou o conceito de comportamento verbal proposto por Skinner.

O capítulo seguinte é dedicado a relatar os fundamentos do cognitivismo e da psicologia cognitiva, proporcionando ao leitor conhecimento acerca dos pressupostos ontológicos e da relação do cognitivismo com o realismo e o determinismo, postulando de forma concisa a visão do cognitivismo acerca do indivíduo e do processamento cognitivo de informações. Aborda ainda, de forma clara, como o processo de representações mentais e o indivíduo são estudados e interpretados, salientando as diferenças entre o homem e o computador. O método hipotético-dedutivo utilizado nesta teoria é também descrito nesse capítulo, assim como o indivíduo é interpretado, sinalizando as divergências e convergências com outras teorias, inclusive na distinção da relação mentecorpo.

O terceiro capítulo é dedicado à psicologia cognitiva e à epistemologia. Nele são apresentados os pressupostos epistemológicos do cognitivismo, enfatizando-se o racionalismo crítico de Popper e sua relação com o cognitivismo, assim como a importância de seu autor, muitas vezes não reconhecida. À luz das idéias de Popper, é discutida a visão do inatismo e do construtivismo, inserindo-se ao longo do subcapítulo as visões sustentadas por Fodor, Piaget e Chomsky a respeito destes temas, visando a uma reflexão do leitor acerca do tema. Inclui-se também neste subcapítulo o conceito de falseabilidade do racionalismo. O capítulo também é destinado ao processo da explicação científica do cognitivismo e a obtenção de conhecimento, mostrando a necessidade da epistemologia para a ciência cognitiva.

O quarto capítulo destina-se a relatar as metodologias das quais a psicologia cognitiva lança mão para estudar seu fenômeno, assim como a importância da simulação computadorizada e da neurociência para a ciência cognitiva. Inicialmente, o capítulo apresenta a interação das subcorrentes cognitivistas e, na seqüência, é abordado de forma precisa o método científico de Popper

\footnotetext{
${ }^{1}$ Endereço para correspondência:

Universidade São Francisco - Programa de Pós-Graduação em Psicologia

Rua Alexandre Rodrigues Barbosa, 45 - 13251-040 - Itatiba-SP
} 
e os atuais, cada um deles sendo dividido em um subcapítulo. Os métodos construtivos e o avanço dos recursos técnicos são descritos nesse capítulo como avanços necessários para a psicologia cognitiva e, como exemplo, é citada a simulação computadorizada. O capítulo é finalizado descrevendo o delineamento experimental de uma pesquisa, assim como a posição da psicologia cognitiva acerca deste, além das contribuições da neurociência no campo da psicologia cognitiva e da ciência cognitiva.

Por fim, no último capítulo, Castanõn faz um fechamento de seus estudos e expõe seu ponto de vista acerca do que foi apresentado. Assim, conclui a obra afirmando o objeto de estudo tanto do cognitivismo quanto da psicologia cognitiva: a consciência, e não o computador. O livro pode ser considerado interessante, indicado àqueles que pretendem compreender mais a respeito dos fundamentos do cognitivismo e das áreas derivadas, tais como a psicologia cognitiva, neuropsicologia e ciência cognitiva. A linguagem utilizada é clara e de fácil compreensão, inclusive para aqueles que não possuem conhecimento algum acerca do cognitivismo, sendo inseridos, ao longo dos capítulos, exemplos que facilitam o entendimento.

Sobre a autora:

Adriana Munhoz Carneiro é graduanda em Psicologia pela Universidade São Francisco e faz parte do Programa de Iniciação Científica como bolsista PROBAIC/ USF. 